\title{
Unfolding Humanity: Mathematics at Burning Man
}

\section{Satyan L. Devadoss and Diane Hoffoss}

\section{Introduction}

In August 2018, a two-ton metal, wood, and acrylic interactive sculpture showcasing unsolved problems of mathematics came to life in the middle of the Nevada desert. Rising 12 feet tall with an 18-foot wingspan, the unfolding dodecahedron was externally skinned with black panels containing 2240 acrylic windows, illuminated by more than 16,000 LEDs that were driven by 20 programmed controllers. The interior, large enough to hold 15 people, was fully lined with a massive mirror over each of the twelve pentagonal faces. With an estimated 6500 person-hours invested and over $\$ 40,000$ in grants and donations raised, the resulting artwork was displayed at Black Rock City, the desert location of Burning Man. This article outlines our journey, two mathematicians embracing the role of amateur sculpture artists.

Burning Man is an arts gathering, founded by Larry Harvey and Jerry James in 1986 on Baker Beach near San Francisco. The rapidly growing event moved to the Nevada desert in 1990, and now attracts more than 70,000 people. Its home is Black Rock City, a temporary metropolis that exists only during the week leading up to Labor Day. Today, this event has become the gold standard for largescale sculpture exhibitions, with much of Silicon Valley in attendance to contemplate the cutting-edge technical and engineering feats [4]. A gathering once viewed as fringe is becoming a well-respected cultural phenomenon. Indeed, the Smithsonian devoted its entire Renwick Gallery to the exhibition No Spectators: The Art of Burning Man, which ran

Satyan L. Devadoss is the Fletcher Jones Professor of Applied Mathematics at the University of San Diego. His email address is devadoss asandiego.edu.

Diane Hoffoss is associate professor of mathematics at the University of San Diego. Her email address is dhoffoss@sandiego.edu.

For permission to reprint this article, please contact: reprint - permission@ams.org.

DOI: https://dx.doi.org/10.1090/noti 1857

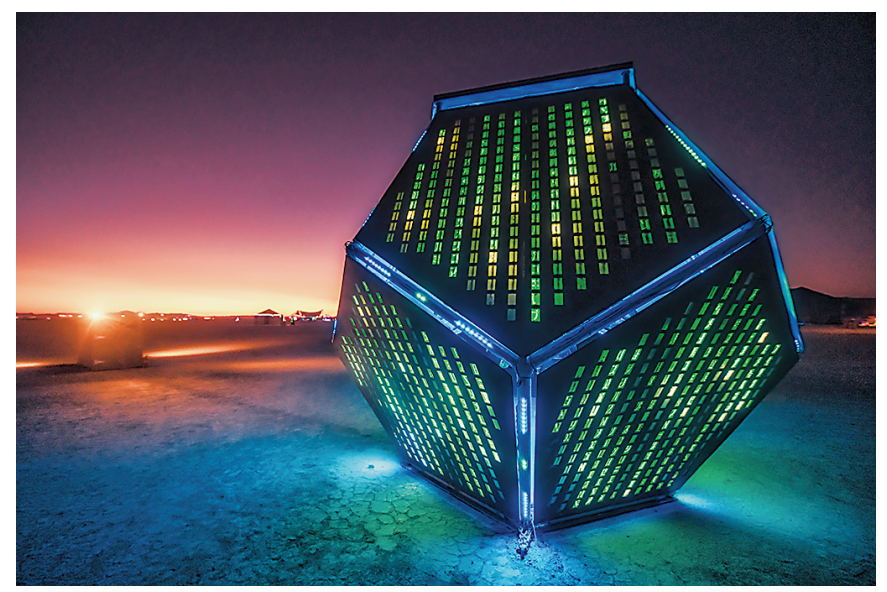

Figure 1. Unfolding Humanity at sunrise in Burning Man 2018, with LED animation along the edges and faces.

from March 30, 2018 to January 21, 2019. This show is now on a national tour, first to Cincinnati and then to Oakland.

\section{Vision}

Our sculpture, titled Unfolding Humanity, calls attention to unsolved problems in mathematics and physics. On one hand, it echoes the renaissance printmaker Albrecht Dürer's explorations nearly 500 years ago on polyhedral nets, providing the earliest known examples of polyhedra unfolded to lie flat for printing. Motivated by this, G. Shephard [9] asks: can every convex polyhedron be cut along some of its edges so that it unfolds into one flat piece without overlap? It is not too difficult to construct nonconvex polyhedra that offer counterexamples: negative (discrete Gaussian) curvature at certain vertices can obstruct the unfolding without overlap [1, Chapter 22].

For the convex case, however, this problem remains enticingly open. Ghomi recently showed that a convex polyhedron can be unfolded once it undergoes an affine transformation [3]. Horiyama and Shoji show that every 


\section{COMMUNICATION}

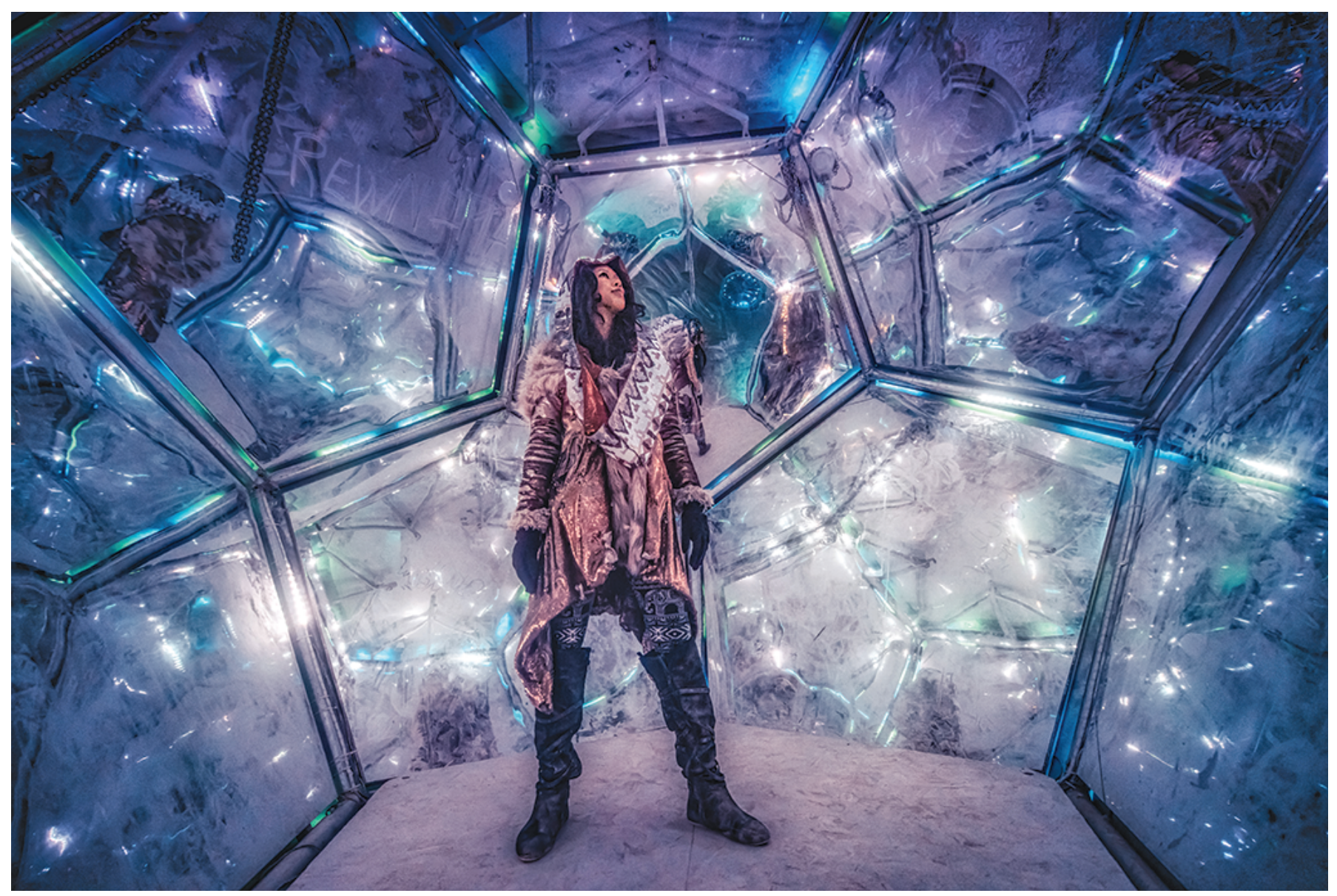

Figure 2. Standing inside the dust-covered Unfolding Humanity with LED animation along the edges.

edge-unfolding of the Platonic solids yields a valid net [5]. In particular, all 43,380 distinct edge-unfoldings of the dodecahedron lay flat. Our sculpture allows participants to unfold eight of the pentagonal panels of the dodecahedron (though not fully flat) to illustrate one such possible configuration.

On the other hand, the sculpture asks the observer to contemplate the shape of our universe. In 2003, data from WMAP, a satellite that measured cosmic microwave background radiation, revealed that the known universe might be modeled by the Poincaré dodecahedral space [7], obtained by identifying antipodal faces of the dodecahedron with a twist. The inside of our dodecahedron is covered with seven-foot-tall mirrors, becoming an illuminated mirrored room designed to allude to this space. While final refinements in 2012 of the WMAP data seem likely to fit with a Euclidean universe (with curvature within $0.4 \%$ of flat), Luminet claims that the data remains consistent with the Poincaré dodecahedral space as well as other finite topological spaces [7]. Of course, the reflections of the mirrors provide a vastly different geometry than the rotational twists needed for Poincaré space, but yet they allow participants to enter a small finite universe, to witness the complex beauty where light folds back upon itself.

\section{Origins}

The past twenty years have brought about a strong intersection between mathematics and the visual arts. Venues for mathematically inspired art have included international conferences (such as Bridges), journals (such as MIT's Leonardo), gallery showcases (including those at the Joint Mathematics Meetings), and more. Although a tremendous amount of art has been based on mathematical ideas that are centuries old, a current trend has many contemporary mathematical artworks and exhibits striving to highlight recent and open mathematics. And so, our motivating question asks, what could it look like for vibrant and unsolved mathematics to be made embodied and physical, to engage the general public?

With Hoffoss's 2017 experience as a Burning Man installation lighting artist, our answer was to take the form of a large-scale sculpture. Fortunately, Devadoss was offering an upper-level mathematics geometry elective in Fall 2017 at the University of San Diego (USD), focusing on discrete and computational geometry. For the course's culminating 
project, student teams submitted conceptual large-scale sculpture proposals satisfying the following constraints:

1. Make it interactive for participants.

2. Address an unsolved question in geometry.

3. Design around the 2018 Burning Man theme of Asimov's I, Robot.

Out of five team project proposals, we chose one with the most potential: a project based on an unfolding dodecahedron by USD students Jordan Abushahla, Nick Bail, and Eugene Wackerbarth. After minor alterations to this proposal, an initial Letter of Intent was put forward to Burning Man in November 2017. Passing the first round of approval, a full proposal was submitted at the end of January 2018, titled Unfolding Humanity. This version now included the iconic 'character rain' animation from The Matrix, an ambitious LED lighting infrastructure, a fully-lined mirrored interior, and a detailed budget.

This duality in the artwork, of technological framework on the outside, with reflections of humanity pondering vastness of space and time on the inside, opens the door to ask deep questions. In par-

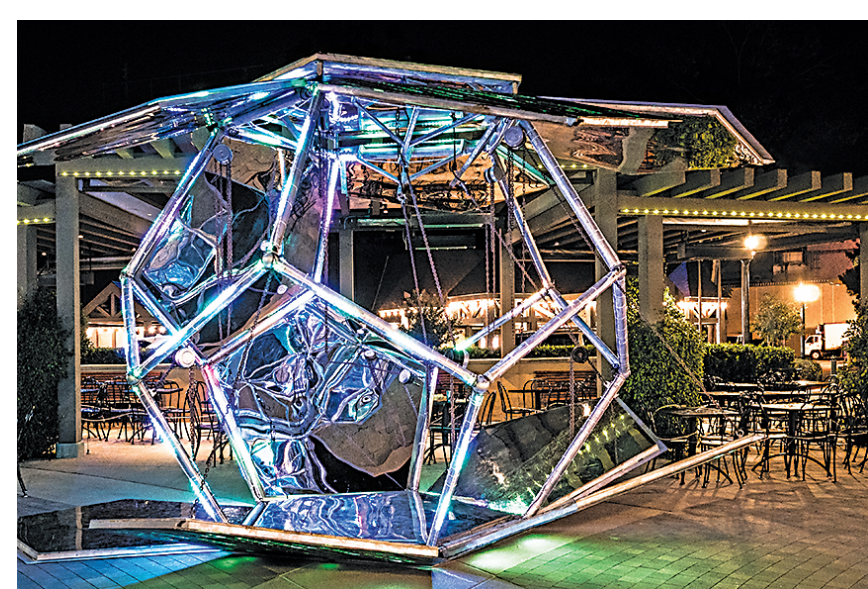

Figure 3. Showcasing Unfolding Humanity at Balboa Park in San Diego, with eight panels open. to handle enthusiastic interactivity from the Burning Man community. Added to this are the brutal desert conditions, with high heat, pervasive dust, and sustained winds of up to $100 \mathrm{mph}$.

The artistic features of the project were created at San Diego CoLab, a collaborative work-space that provided a dedicated build space, the use of many production quality tools and machinery, and access to skilled builders who offered expertise and advice. Although we orchestrated it, nearly all the work performed at CoLab was done by community drop-in volunteers. Each of the pentagonal faces were CNC routed, with 224 precisely spaced windows cut out to hold illuminated characters (which themselves were individual acrylic panes laser cut and etched on a large laser bed with one of 72 different characters). The faces were painted, acrylic panes glued, wiring installed, and LED strips cut from long spools and soldered into 235 special lengths strips. Microcontrollers were soldered with appropriate connectors, and then programmed to communicate with one another and to drive the LED animations on the faces and the edges.

The construction work did ticular, the sculpture invites the participant to explore ways technology plays a role in illuminating and controlling our lives, and the quest to be truly human and free. Basing the artwork on unsolved problems in mathematics and physics gives greater weight to its voice.

\section{Creation}

With a conceptual design in mind, we reached out to students at USD for help. Soon afterwards, faculty members and the San Diego community at large were drawn in, to participate in the development, creation, and construction. There were roughly three global issues to consider:

1. the metal framework and its kinematics,

2. the pentagonal faces and lighting infrastructure, and

3. the transportation, build, and tear down at Burning Man.

During Spring and Summer 2018, engineering faculty, students, and alums took the lead in modeling, testing, and building the metal structure. The steel framing for the pentagonal faces was manufactured at USD, and the 20 vertices (with three edges emanating from a vertex, each at $108^{\circ}$ from the other two) were commissioned to be custom welded. The structural design was further constrained by additional needs: for dismantling and reassembly, for the kinematic ability to unfold, and not least for rigidity not end in San Diego, however. A team of 18 volunteer builders was recruited to travel to Burning Man to unload, assemble, test, troubleshoot, support, disassemble, and repack the structure into a moving truck. During the week of Burning Man, considerable volunteer hours were invested in maintaining the sculpture, including troubleshooting and repairing the (three repeatedly failing) generators for the project, refueling the generators, cleaning and clearing the interactive chain hoists, replacing and repairing damaged LED strips, and cleaning mirrors of dust.

In all, the sculpture was conceived, designed, and built by more than 80 volunteers: five faculty members, 20 students and alums, and more than 55 members of the San Diego and Bay Area communities. An estimated total of 6500 person-hours was invested in this project by our volunteers. The cost for the project was over $\$ 40,000$, with $\$ 10,000$ from the San Diego Collaborative Arts Project, $\$ 5000$ from USD Humanities Center, and $\$ 15,000$ from the Fletcher Jones Applied Mathematics endowment. Most notably, community members donated more than $\$ 10,000$.

\section{Conclusion}

At Burning Man, outside of the hottest parts of the days, there was a constant stream of visitors to the artwork. Most 
of them were curious about all aspects of the piece, and constantly engaged the build volunteers with follow-up questions, both about the unfolding mathematics and the unknown cosmology. Many of these interactions led to rather long discussions about either the nature of mathematics itself, or what it meant for the universe to have a shape and what other possible shapes might be. After Burning Man, Unfolding Humanity was also showcased in downtown San Diego in October 2018, in the famous Balboa Park, outside the Old Globe Theatre; see Figure 3. The final resting place for this artwork is currently being discussed.

Several mathematics research problems were also investigated around unfolding geometry. For instance, a visual algorithm was developed that proved that every unfolding of an $n$-cube is without overlap, resulting in a valid net [2]. Work is in progress to show that every unfolding of all regular polytopes is possible. These explorations also resulted in conversations with artists, some leading to gallery shows [8]. Overall, Unfolding Humanity was a remarkable success, showcasing not only the interplay between engineering, mathematics, and the arts, but the collaboration between academia and the arts community. A video showcasing this work can be found in [10].

Based on our experience, we offer interested readers pursuing similar projects of their own a few closing thoughts. First, get connected with your local art community. We have found most artists and makers to be very interested in hearing about mathematics, especially topics that avoid technical or computational issues. In particular, there is a great thirst for understanding ideas and questions that are open and accessible for exploration.

Second, try to introduce physical aspects of mathematics to students. There is now a national 'maker space' movement, led by Stanford's d.school, that is trickling into the mathematics realm. There are versions of math laboratories at several colleges and universities (which can be traced back to the University of Minnesota's famous Geometry Center) that try to bring an intersection of mathematics with other disciplines in a physical space.

And finally, be bold. In our experience as true amateurs in the sculpture world, we found tremendous encouragement and support. The art and maker communities are wonderfully enthusiastic and deeply gifted. Most likely, the help you need will be found, and those helping you will be grateful for the experience, for both the entry into mathematics and the building of community.
ACKNOWLEDGMENTS. This project was a deeply collaborative effort, with eighty volunteers and a faculty leadership team of Susie Babka, Gordon Hoople, and Nate Padre in addition to the authors. We are grateful for all involved, and especially thankful for the contributions from Max Elliott, Lee Hemingway, and Quinn Pratt, as well as Gilles Bonugli Kali (instagram@gbk. style) for his photography. We are also indebted to USD, San Diego Collaborative Arts Project, and San Diego CoLab for their trust and support of this endeavor. Finally, this project is dedicated to our students, who have shown deep sacrifice and love, from its conception to its creation.

\section{References}

1. Demaine E, O'Rourke J. Geometric Folding Algorithms, Cambridge University Press, 2007.

2. DeSplinter K, Devadoss S, Readyhough J, Wimberly B. Unfolding cubes: nets, packings, and chords, preprint 2018.

3. Ghomi M. Affine unfoldings of convex polyhedra, Geometry and Topology 18 (2014) 3055-3090.

4. Holson L. How Burning Man has evolved over three decades, The New York Times, August 30, 2018.

5. Horiyama T, Shoji W. Edge unfoldings of Platonic solids never overlap, Canadian Conference on Computational Geometry 23 (2011).

6. Luminet J. The Status of Cosmic Topology after Planck Data, https://arxiv.org/pdf/1601.03884.pdf.

7. Luminet J, Weeks J, Riazuelo A, Lehoucq R, Uzan J. Dodecahedral space topology as an explanation for weak wide-angle temperature correlations in the cosmic microwave background, Nature 425 (2003) 593-595.

8. Schuh O. Unfolding a Cube, Silas von Morisse Gallery (solo exhibit), October 27-November 17, 2018.

9. Shephard G. Convex polytopes with convex nets, Mathematical Proceedings of the Cambridge Philosophical Society 78 (1975) 389-403.

10. https://protect-us . mimecast. com/s/AY6aCpYojOFMBZmi P0ZXH?domain=sandi ego. edu.

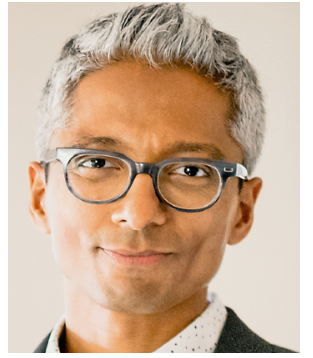

Satyan L.

Devadoss

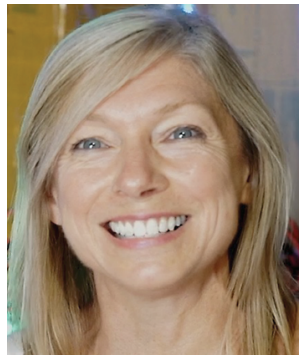

Diane Hoffoss

\section{Credits}

Figures 1 and 2 are by Gilles Bonugli Kali.

Figure 3 is by Satyan L. Devadoss.

Photo of Satyan L. Devadoss is courtesy of the author.

Photo of Diane Hoffoss is by Rand Larson, RandLarson. com. 